\title{
Meester en gezel: op zoek naar verbeteringen in de rol van de klinisch docent
}

\author{
G.B.S. Penders, N. van Dijk, B. de Doelder
}

\section{Samenvatting}

Inleiding: Doceren is inherent aan het beroep van arts. De rol van de klinisch docent is echter niet duidelijk omschreven.

Methode: Door middel van een literatuurstudie en een forumdiscussie naar aanleiding van stellingen is gezocht naar de eigenschappen van de ideale klinisch docent.

Resultaten: De eigenschappen van een goede klinisch docent zijn niet voor iedereen gelijk. Begeleiding van co-assistenten door arts-assistenten heeft voor-en nadelen. Er is een voorkeur voor begeleiding door ervaren stafleden met algemeen medische kennis en voldoende ervaring met het geven van feedback. Het staflid is tevens rolmodel voor de student in verschillende rollen: geneeskundige, supervisor, onderwijzer en persoon. De co-assistent neemt naar eigen inzicht van verschillende rolmodellen verschillende eigenschappen over. De voorkeur van studenten voor een van de rollen verschuift van de onderwijzende rol in de doctoraalfase naar een superviserende rol aan het einde van de opleiding. Degelijke begeleiding en feedback zijn noodzakelijk voor een onderwijskundig verantwoord co-assistentschap.

Conclusie: Co-assistenten hebben goede begeleiding van goede klinisch docenten nodig. Hiertoe moet iedere medicus in de basisopleiding reeds getraind worden in het geven van onderwijs en feedback en moeten klinisch docenten zich bewust zijn van hun functioneren als rolmodel. (Penders GBS, Dijk N van, Doelder B de. Meester en gezel: op zoek naar verbeteringen in de rol van de klinisch docent. Tijdschrift voor Medisch Onderwijs 2002;21(4):195-200.)

\section{Inleiding}

Onderwijs in de klinische fase is variabel, onvoorspelbaar, ad hoc en niet continu. Dit blijkt uit de literatuur over klinisch onderwijs. ${ }^{1}$ Het onderwijsprogramma is de afgelopen jaren op alle faculteiten gemoderniseerd. Goed klinisch onderwijs loopt echter nog steeds niet langs gebaande paden. ${ }^{2}$ De co-assistentschappen hebben vanouds een bijzondere status binnen het medisch onderwijsprogramma.

Klinisch onderwijs wordt verzorgd door zowel onervaren arts-assistenten als medisch specialisten met veel (onderwijs)ervaring. Waar er in de eerste vier jaren veel aandacht is voor de kwaliteit van docenten, is in de klinische fase iedere clinicus automatisch klinisch docent. De kwaliteit van het klinisch onderwijs is geheel afhankelijk van die docenten. ${ }^{2}$ Men volgt daarvoor geen opleiding en de rol van de docent is niet duidelijk omschreven. Eigenlijk onbegrijpelijk, omdat onderwijs geven inherent is aan het beroep van arts.

Het Landelijk Overleg Co-Assistenten (LOCA) en het Studentbestuursleden Overleg Geneeskunde (SOG) gingen op zoek naar de eigenschappen van de ideale klinisch docent.

\section{Methode}

Het SOG en het LOCA hebben een forumdiscussie georganiseerd tijdens het NVMO-congres 2001. Vooraf is de literatuur bestudeerd en zijn stellingen geformuleerd. Aan de hand van de stellingen is een discussie gevoerd over de eigenschap- 
pen van een goede klinisch docent. Deelnemers aan de discussie waren de vier forumleden, twee co-assistenten (A. Schreijer en M. Swennen) en twee medisch specialisten (E. ter Braak en L. Verschoor) en daarnaast zo'n zestig medisch studenten, (klinisch) docenten en onderwijskundigen. De forumleden hebben op basis van hun ervaring en wetenschappelijke literatuur gereageerd op de volgende stellingen:

- Co-assistenten kunnen prima begeleid worden door arts-assistenten.

- De belangrijkste rol van de klinisch docent is die van rolmodel.

- De klinisch docent: meester of metgezel?

- Leren is niet meekijken, maar vooral zelf doen.

In dit artikel worden de resultaten van het literatuuronderzoek en de discussie weergegeven.

\section{Resultaten}

\section{Algemeen}

Niet iedereen heeft dezelfde preferenties voor eigenschappen van de klinisch docent. Zowel onderwijsgevers als -ontvangers verschillen in hun individuele voorkeuren. In de literatuur zijn verschillende onderzoeken naar de eigenschappen van een goede klinisch docent beschreven. ${ }^{3-5}$ Een goede docent geeft blijk van een juiste attitude, is betrokken bij het werk van de co-assistent, daagt uit en stimuleert. ${ }^{3-5}$ Co-assistenten benadrukken het belang van didactische vaardigheden van de docent. ${ }^{3}$ Door een opvallend klein deel van de co-assistenten (12\%) wordt veel kennis als eigenschap van de ideale begeleider genoemd. ${ }^{3}$ Studenten en eerstejaars arts-assistenten vinden dat een goede klinisch docent een brede medische kennis heeft, plezier heeft in patiëntenzorg en onderwijs en enthousiast is. ${ }^{4}$

\section{Co-assistenten kunnen prima begeleid worden door arts-assistenten}

De co-assistentschappen zijn een onderwijsperiode en niet alleen een meeloopperiode. Dit betekent dat goede docenten worden ingezet en dat goede feedback op het functioneren van de co-assistent noodzakelijk is. Het betekent ook dat structureel onderwijs gekoppeld dient te worden aan de ervaringen van de co-assistent. ${ }^{6}$ De visitatiecommissie is van mening dat klinisch ervaren docenten een belangrijke rol dienen te spelen. ${ }^{6}$ Echter, in de praktijk zijn arts-assistenten vaak de belangrijkste begeleiders van co-assistenten. ${ }^{7}$

Voordeel van de arts-assistent als begeleider is het laagdrempelig contact tussen co-assistent en arts. Co-assistenten vinden het niet noodzakelijk dat de klinisch docent veel vakspecifieke kennis heeft. ${ }^{3}$ Het is belangrijker dat een docent algemene relevante klinische kennis heeft. ${ }^{8}$ Arts-assistenten bezitten deze algemene kennis ook en zouden de co-assistent dus prima kunnen begeleiden. Het klinisch denken van de arts-assistent verloopt minder middels herkenning en ervaring dan bij de medische staf. In de discussie kwam naar voren dat de arts-assistent vaak, net als de co-assistent, stapsgewijs denkt. Het voordeel is dat de co-assistent zo beter inzicht krijgt in de stappen van het medisch denken.

Daartegenover staat dat eigenlijk iemand met veel klinische ervaring de co-assistent moet begeleiden bij het aanleren van vaardigheden. Medisch specialisten hebben meer ervaring met het geven van feedback aan co-assistenten dan arts-assistenten. Jonge artsen staan nog te weinig 'boven de stof' en kunnen vaak weinig tijd voor begeleiding vrijmaken.6 910 De medische staf durft meer uit handen te geven aan de co-assistent. De jonge arts moet zelf ook nog veel ervaring opdoen en zal minder aan de co-assistent 
overlaten, zo meldden zowel co-assistenten als docenten tijdens de discussie. Op basis van jarenlange klinische ervaring demonstreert de clinicus een eigen stijl van klinische beroepsuitoefening, waarvan de co-assistent onderdelen kan imiteren. Een arts-assistent heeft nog geen eigen stijl van klinische beroepsuitoefening en kan zo nog geen voorbeeld voor de co-assistent zijn. ${ }^{6}$

In de praktijksituatie moet de student gecontroleerd worden tijdens het uitvoeren van klinische vaardigheden. Om deze reden lijkt de suggestie een ervaren verpleegkundige als begeleider van de co-assistent in te zetten ontoereikend. Verpleegkundigen bezitten andere vaardigheden dan artsen en de vraag is of zij voldoende feedback op het goede niveau kunnen geven op het handelen van de student.

Lang niet iedereen is een natuurtalent en zal goede feedback kunnen geven. Onderwijs geven is een aparte specialiteit en aan de scholing van docenten moet veel meer aandacht worden besteed. De beleidsmatige vraag is in wie geïnvesteerd moet worden bij trainingen. De arts-assistent is snel weer weg en de investering gaat dan verloren voor het specifieke opleidingsziekenhuis. Maar de assistent krijgt later wel ergens een onderwijsfunctie. De investering in stafleden is zonder meer de moeite waard. Omdat alle artsen later onderwijs geven, zouden didactische vaardigheden voor iedereen eigenlijk onderdeel van de basisopleiding moeten zijn.

\section{De belangrijkste rol van de klinisch do- cent is die van rolmodel}

'Voorbeelden zijn niet de belangrijkste methode om gedrag te beïnvloeden, het is de enige methode.' Albert Schweitzer heeft hiermee het belang van rolmodellen al lang geleden benadrukt. ${ }^{11}$ Een goede attitude demonstreren is de belangrijkste functie van een effectief rolmodel in de klinische fase: 'De dokter moet gewoon dokter zijn'. ${ }^{8}$ Rolmodellen zijn een krachtige onderwijstechniek, die speciaal geschikt is voor de co-assistentschappen. ${ }^{12}$ 13 Door verschillende stijlen van personen ontstaan er binnen dezelfde rol grote verschillen. Dit is ook wenselijk, zo kunnen studenten afhankelijk van situatie en leerdoel een ander rolmodel kiezen. ${ }^{13}$ Een grotere diversiteit aan modellen geeft studenten de mogelijkheid zich een beeld te vormen van de arts die zij zouden willen zijn. Ze kunnen een keuze maken met welke eigenschappen ze zich wel en met welke ze zich niet willen identificeren. De co-assistent neemt van verschillende begeleiders verschillende eigenschappen over, zo is ook de ervaring van de deelnemers uit de zaal.

De eigenschappen van klinisch docenten kunnen teruggevoerd worden op vier verschillende rollen: geneeskundige, supervisor, onderwijzer en persoon. ${ }^{14}$

In de rol van geneeskundige demonstreert de docent een eigen stijl van klinische beroepsuitoefening. De student kan ervoor kiezen dit gedrag al of niet te imiteren. ${ }^{12}$ Co-assistenten ergeren zich als de clinicus 'slecht' gedrag demonstreert. 515 Voor deze rol moet de docent een brede algemeen medische kennis hebben en klinisch competent zijn. In deze rol is een goede attitude ten opzichte van patiënt, collega's en medische wetenschap van belang. 14

In de rol van supervisor zorgt de klinisch docent voor het structureren van de leer- en werkomgeving. De supervisor stelt de co-assistent in de gelegenheid vaardigheden uit te voeren. Het geven van zelfstandigheid en verantwoordelijkheid is hierbij belangrijk. ${ }^{3} 14$ De co-assistent wordt door een goede supervisor betrokken bij de medische besluitvorming en 
wordt in staat gesteld problemen op te lossen en besluiten te nemen. Door nabespreking van het klinisch denkproces van de co-assistent en feedback op het medisch handelen draagt de supervisor bij aan het verdiepen en optimaliseren van de kennisstructuur. ${ }^{12} 14$

Als onderwijzer moet de klinisch docent goede vaardigheden en attitudes tonen, de belangrijke aspecten van deze vaardigheden kunnen demonstreren en de resultaten ervan kunnen bespreken. ${ }^{12}$ De docent moet tijd nemen om uitleg te geven en aansluiten bij het kennisniveau van de coassistenten. Docenten moeten over didactische vaardigheden beschikken en goed onderwijs geven. Studenten waarderen het wanneer de docent een goed verhaal heeft en zij actief betrokken worden bij het onderwijs. ${ }^{15}$ Van de docent wordt interesse in medisch onderwijs verwacht.

Als persoon moet de klinisch docent een ontspannen sfeer scheppen en de student geruststellen. ${ }^{15}$ Goede docenten voor deze rol zijn bereikbaar, vriendelijk, behulpzaam en laagdrempelig. ${ }^{14}$ Hij of zij moet het leuk vinden om een co-assistent te begeleiden. Het is van belang dat de docent enthousiast is en belangstelling toont voor de co-assistent. ${ }^{3}$

Het gebruik van rollen is inherent aan het onderwijs in de kliniek. Rolmodellen kunnen zowel een positieve als een negatieve invloed hebben. Om rolmodellen als effectief onderwijsmiddel te gebruiken moeten clinici zich er voortdurend van bewust zijn dat hun handelen studenten beïnvloedt. ${ }^{13}$

\section{De klinisch docent: meester of metgezel?}

De voorkeur van studenten voor een van bovenstaande rollen verschuift van de onderwijzende rol in de doctoraalfase naar een superviserende rol aan het einde van de co-assistentschappen. 816 Het Learning Vector Model van Stritter impliceert dit: studenten ontwikkelen zich van een positie waarin zij zich afhankelijk opstellen ten opzichte van hun docent, via een positie van samenwerking, tot een positie waarin zij zelfstandig hun leerbehoeften nastreven. ${ }^{17}$ De Utrechtse co-assistenten bevestigen dit: zij willen naarmate hun co-assistentschappen vorderen steeds meer verantwoordelijkheid dragen en meer medische handelingen zelf uitvoeren. ${ }^{3}$

\section{Leren is niet meekijken, maar vooral zelf doen.}

'See one, do one, teach one' is jarenlang gehanteerd als dogma voor het onderwijzen van technische vaardigheden. Co-assistenten stellen het op prijs veel zelfstandigheid te krijgen en veel medische handelingen te mogen verrichten. ${ }^{3}$ Het werkt motiverend wanneer je je ambities kunt verwezenlijken en motivatie is de sleutel tot zelfgestuurd leren. ${ }^{8}$

Om vaardigheden goed te leren beheersen moet je vaardigheden goed aangeleerd krijgen. Naast een goed voorbeeld en veel zelf doen is de nabespreking belangrijk. De handigheid leer je door het doen, maar de achtergronden en toepassing leer je alleen door nabespreken. In de praktijk blijkt echter dat studenten weinig feedback krijgen. Daarnaast klagen zij dat zij weinig vaardigheden gedemonstreerd krijgen en vaak slecht geïnstrueerd worden. ${ }^{7}$ De ideale klinisch docent instrueert de co-assistent goed, laat hem/haar veel zelf doen en bespreekt verrichte handelingen na met de co-assistent.

\section{Conclusie}

Co-assistenten zijn aangekomen in de laatste fase van hun opleiding en willen ter voorbereiding op de nabije praktijk steeds meer verantwoordelijkheid dragen. Om dit te bereiken hebben ze goede begeleiding en veel feedback nodig van goede 
klinisch docenten. Niet iedereen heeft dezelfde preferenties voor de eigenschappen van de klinisch docent. Zowel onderwijsgevers als -ontvangers verschillen in individuele voorkeuren.

Klinisch ervaren docenten dienen een belangrijke rol te spelen binnen het co-assistentenonderwijs. Begeleiding door artsassistenten, zoals dat momenteel in de praktijk veel plaatsvindt, heeft voor- en nadelen.

Een belangrijke functie van de klinisch docent is die van rolmodel. Rolmodellen zijn de belangrijkste manier om normen en waarden van de professie over te brengen. De co-assistent komt verschillende rolmodellen tegen en kan hieruit een eigen stijl ontwikkelen. De docent moet zich bewust zijn van zijn/haar functie als rolmodel. Om een goed rolmodel te kunnen zijn is training een vereiste. De voorkeur verschuift gedurende de opleiding van de onderwijzende rol naar de superviserende rol.

De ideale klinisch docent instrueert de co-assistent goed, laat hem/haar veel zelf doen en bespreekt verrichte handelingen na met de co-assistent. Lang niet iedereen is bij voorbaat een goede begeleider en zal meteen goede feedback kunnen geven. Er moet energie gestoken worden in het ontwikkelen van de didactische vaardigheden van assistenten en stafleden. Omdat alle artsen onderwijs geven, is het logisch dat didactische vaardigheden in de basisartsopleiding worden opgenomen.

\section{Literatuur}

1. Irby DM. Teaching and learning in ambulatory care settings: a thematic review of the literature. Acad Med 1995;70:898-931.

2. Essed GGM. Stages. In: Metz JCM, Scherpbier AJJA, Vleuten CPM van der, redactie. Medisch onderwijs in de praktijk. Assen: Van Gorcum; 1995. p. 108-111.
3. Vink GR, Witte DR, Blenke EJSM, Dijk RR van. Meningen over het ideale co-assistentschap. Tijdschrift voor Medisch Onderwijs 2000;19:20812.

4. Irby DM, Ramsey PG, Gillmore GM, Schaad D. Characteristics of effective clinical teachers of ambulatory care medicine. Acad Med 1991;66:54-5.

5. Irby DM. Clinical teacher effectiveness in medicine. J Med Educ 1978;53:808-15.

6. VSNU-Visitatiecommissie geneeskunde en gezondheidswetenschappen. Onderwijsvisitatie geneeskunde en gezondheidswetenschappen. Utrecht: Vereniging van Samenwerkende Nederlandse Universiteiten; 1997. p. 24-27, 49-52.

7. Remmen R, Denekens J, Scherpbier A, Hermann I, Vleuten $C$ van der, Royen $P$ van, et al. An evaluation study of the didactic quality of clerkships. Med Educ 2000;34:460-4.

8. Parsell G, Bligh J. Recent perspectives on clinical teaching. Med Educ 2001;35:409-14.

9. Wilkerson L, Irby DM. Strategies for improving teaching practices: a comprehensive approach to faculty development. Acad Med 1998;73:387-96.

10. Gulden JWJ van der, Bulte JA, Metz JCM. Vragen bij het onderwijs aan co-assistenten. Ned Tijdschr Geneeskd 1989;133:564-7.

11. Mandsley RF. Role models and the learning environment: essential elements in effective medical education. Acad Med 2001;76:432-4.

12. Irby DM. Clinical teaching and the clinical teacher. J Med Educ 1986;61:35-45.

13. Ficklin FL, Browne VL, Powell RC, Carter JE. Faculty and house staff members as role models. J Med Educ 1988;63:392-6.

14. Ullian JA, Bland CJ, Simpson DE. An alternative approach to defining the role of the clinical teacher. Acad Med 1994;69:832-8.

15. Metcalfe DH, Matharu M. Student's perception of good and bad teaching: report of a critical incident study. Med Educ 1995;29:193-7.

16. Paukert JL, Richards BF. How medical students and residents describe the roles and characteristics of their influential clinical teachers. Acad Med 2000;75:843-5.

17. Stritter FT, Baker RM, Shahady EJ. Clinical Instruction. In: McGaghie WC, Frey JJ, editors. Handbook for the academic physician. New York: Springer Verlag; 1988. p. 98-124.

De auteurs:

Drs. G.B.S. Penders, co-assistent in het Universitair Medisch Centrum St. Radboud, Nijmegen en bestuurslid van het Landelijk Overleg Co-Assistenten (LOCA).

Mw. drs. N. van Dijk, co-assistent in het Academisch Medisch Centrum Amsterdam en bestuurslid van het Landelijk Overleg Co-Assistenten (LOCA). 
Mw. B. de Doelder, student in het Universitair Medisch Centrum St. Radboud, Nijmegen en bestuurslid van het Studentbestuursleden Overleg Geneeskunde (SOG).

Forumleden:

Mw. dr. E. ter Braak, internist in het Universitair Medisch Centrum Utrecht.

Mw. drs. A. Schreijer, co-assistent in het Academisch Medisch Centrum Amsterdam.

Mw. drs. M. Swennen, co-assistent in het Universitair Medisch Centrum Utrecht.
Dr. L. Verschoor, internist in het Rijnstate ziekenhuis Arnhem.

\section{Correspondentieadres:}

G.B.S. Penders, Heerendonklaan 205, $5223 \mathrm{ZZ}$ 's Hertogenbosch,073-6212626, JurriaanPenders@hotmail.com

\section{Summary}

Introduction: Teaching is an inherent aspect of the medical profession. There is, however, no clear definition of the role of the clinical teacher.

Methods: We tried to identify the qualities of the ideal clinical teacher through a literature study and a forum discussion.

Results: Medical students have different preferences for the qualities of a good clinical teacher. Residents have advantages and disadvantages as clinical teachers. Preferably, medical students should be coached by clinicians who have an extensive general medical knowledge and are experienced in giving feedback. Clinical staff also act as role models. The student will adopt different characteristics from different role models. During medical education teachers play different roles: as physician, supervisor, teacher and person. Medical students' preference for one of these roles shifts from that of teacher in the preclinical phase and the early stages of clinical education to the role of supervisor at the end of clinical training. Appropriate guidance and feedback are indispensable for a didactically sound clerkship.

Conclusion: Medical students need good guidance from good clinical teachers. Training in didactics and giving feedback should be a component of basic medical training. Clinicians should be fully aware of their function as role models for students. (Penders GBS, Dijk N van, Doelder B de. Master and apprentice: in search of the ideal clinical teacher. Dutch Journal of Medical Education 2002;21(4):195-200.) 